\title{
Chapter 12 \\ Reinventing Library Research Support Services at Griffith University
}

\author{
Belinda Weaver \\ D https://orcid.org/0000-0002-6156-7997 \\ Griffith University, Australia \\ Joanna Richardson \\ (iD) https://orcid.org/0000-0002-1871-6707 \\ Griffith University, Australia
}

\section{EXECUTIVE SUMMARY}

Griffith University provides advice and services to researchers around research grants, ethics and integrity, research performance, and publications and outputs. A broad-based researcher education and development program helps inform and upskill researchers and research students. From 2019, Griffith University Library has developed new services to support data-driven, data-intensive research and assist researchers through the entire research lifecycle. This chapter describes the staffing structure and the ideas underpinning a new service catalogue based around key areas, such as data management, open scholarship, and data wrangling. Methods to achieve this included a collaboratively developed knowledge base, the development of new workshops, mapping of research environments and referral pathways, and developing support for researchers for whom there is no established tool for the kinds of research they want to do. A push to establish the library as a vital and valued partner in research projects was a key driver for change.

\section{INTRODUCTION}

Since the seminal report by Megan Oakleaf (2010) on the need for academic libraries to articulate not only their value to their respective institutions but also 'their contribution to institutional mission and goals' (p. 6), librarians have been re-examining their support services for staff and students. Given the 
importance of research performance as one of the key criteria in the major global university ranking schemes, support for researchers has become an important focus. In some universities, libraries have succeeded in being regarded as essential to research processes (Fernández-Marcial, Costa, \& GonzálezSolar, 2016).

The following chapter examines how recent significant changes at Griffith University in both its top-level organisational structure and strategic direction have provided the Library with an opportunity to rethink its research support services. The authors have described a new service model which is currently being implemented, with particular attention given to the ways it contributes to the University's strategic research goals. They conclude with a brief discussion of important additional work which is being planned for 2020 onwards.

\section{CONTEXT}

While this chapter has been written from an Australian perspective, many of the drivers for the evolution of research support services are common across the world's developed and developing nations. Striving to be more productive and more competitive, nations seek to address the major social, economic, and environmental challenges of this century. A government's support for research and innovation helps position a nation to achieve these goals.

At the turn of this century, the Australian Government recognised that to 'create research infrastructure to enhance the national innovation system and to foster collaboration' (Australia. Department of Innovation, Industry, Science and Research, 2010, p. 7), it would be cost-effective and efficient to adopt a national approach to investing in major research facilities and the associated supporting infrastructure and networks. To this end, it created the National Collaborative Research Infrastructure Strategy (NCRIS) (Australia. Department of Innovation, Industry, Science and Research, 2010), the aim of which was to provide researchers with access to world-class resources.

Since most public research in Australia is undertaken by universities (O'Brien, 2010), these institutions were understandably eager to leverage this strategic national investment to benefit their researchers. With the advent of the data deluge, universities submitted funding bids in their own right or collaboratively with other research partners. Importantly, librarians quickly realised that they, too, could play an integral role as members of proposed project teams (Wolski, Richardson, \& Rebollo, 2011).

The next section outlines the current Australian research environment.

\section{Australian Research Environment}

The main research funding body in Australia is the Australian Research Council (ARC), a Commonwealth entity within the Australian Government established as an independent body under the Australian Research Council Act 2001. The ARC advises the Government on research matters and administers the National Competitive Grants Program (NCGP), a significant component of Australia's investment in research and development.

Through Excellence in Research for Australia (ERA), the ARC is also tasked with identifying excellence in research, by benchmarking Australia's university research efforts against their international peers, creating incentives to improve the quality of research, and identifying emerging research areas and opportunities for further development. Clinical and other medical research is primarily supported 
Reinventing Library Research Support Services at Griffith University

by the National Health and Medical Research Council (NHMRC), which also administers and issues significant grant funding to Australian universities and research institutes.

The increasingly computational and data-intensive nature of modern research was identified as early as 2009 by Hey, Tansley, \& Tolle (2009) who argued that there should be a new addition - data exploration - to the three existing models of scientific enquiry: empiricism (describing natural phenomena), theoretical science (based on models and generalised theories) and computational science (simulating complex phenomena):

The world of science has changed ... The techniques and technologies for such data-intensive science are so different that it is worth distinguishing data-intensive science from computational science as a new, fourth paradigm for scientific exploration (p. 15).

In data-intensive science, data is captured by instruments or generated by simulators, and the outputs are too large to be processed by humans. Data thus has first to be manipulated by statistical software and analytical tools such as data mining, visualisation, and simulation in order for researchers to make sense of it. The wide acceptance of Hey et al.'s 'fourth paradigm', data-intensive scientific model (2009) is reflected in Australian research and infrastructure funding. Over the past fifteen years, AUD \$3.3 billion has been invested in NCRIS (Australia. Department of Education and Training, 2019), which established a roadmap for infrastructure support for research. More than AUD \$1 billion has also been made available through co-investment from state and territory governments, universities, research facilities, and industry. The ultimate objective is to support high-quality research that will drive greater innovation in the Australian research sector and the economy more broadly.

Through NCRIS, the Government works with the research sector to drive research excellence and its application. Given the growth in importance of computer-based data gathering and data analysis in most disciplines (Boulton et al., 2012; Katz et al., 2017), developing researchers' skills in these areas is essential to meet that aspiration. Supported by NCRIS, the Australian Research Data Commons (ARDC, 2019) worked with Universities Australia and the Council of Australasian University Directors of Information Technology (CAUDIT) to run a two-day skilled research workforce summit in July 2019. The summit aimed to answer the question: "What skills will our researchers, data or software specialists and research support staff need to survive and thrive in this new world of data-enabled research?" and to come up with concrete proposals and pathways to plan for the future research workforce. This was a belated recognition by Australian universities that workforce issues are beginning to put pressure on the ability of research teams to undertake certain kinds of research.

For example, there are increasing numbers of researchers for whom there is no established tool for the kind of research they want to do. Researchers in disciplines with long-established digital tools, tools such as SPSS, Galaxy, NVivo, MATLAB, or one of the many Virtual Laboratories available to Australian researchers, can generally access online help, starter tutorials, and troubleshooting tips. But in many data-driven disciplines now, researchers need to build their own tools. As MacArthur (2009) observed more than ten years ago:

If you intend to be at the head of your field, you'll often be in a place where the right tools for the job simply don't exist yet. You need to be able to develop such tools yourself, or at least speak the right language to communicate your needs to someone who can; and speaking that language means having a good working knowledge of computation. 


\section{Reinventing Library Research Support Services at Griffith University}

Staff at Griffith University Library are investigating ways to support researchers who are embarking on this path.

\section{Griffith University}

Located in the rapidly growing corridor between Brisbane and the Gold Coast in Southeast Queensland, Griffith University is a comprehensive, research-intensive university with a strong emphasis on interdisciplinarity. Formally founded in 1971, Griffith opened its doors in 1975, introducing Australia's first degrees in environmental science and Asian studies. Currently, the University offers more than 200 degrees across five campuses to more than 50,000 students from 130 countries studying at undergraduate through to doctoral level in one of four broad academic groups: arts, education and law; business; science; and health. The University operates on a trimester schedule.

A series of prestigious rankings systems place Griffith in the top 2 percent of universities worldwide: ranking 35th in the 2019 Times Higher Education Young University Rankings (Times Higher Education, 2019) and 37th in the 2020 QS World University Rankings Top 50 Under 50 (Quacquarelli Symonds, 2019). Griffith's strategic research investment strategy has positioned it to be a world leader in the fields of Asian politics, trade and development; climate change adaptation; criminology; drug discovery and infectious disease; health; sustainable tourism; water science; music; and the creative arts.

The mission of Griffith University is to "engage in outstanding scholarship that makes a major contribution to society and to produce groundbreaking research. Students will be provided with an excellent education and the capacity to develop and apply knowledge to exercise influence and make meaningful life-long contributions to their communities'. In order to deliver on its mission, the University's Griffith (Griffith University, 2019) is structured around six interrelated core commitments: values, students, research, people, engagement, and infrastructure.Figure 1 depicts the University's current organisation structure. The University Librarian reports to the Senior Deputy Vice Chancellor.

However, at the time of writing, the University is in the process of transitioning to a new senior executive leadership team, which will not be fully in place until early 2021. The current Senior Deputy Vice Chancellor role will be replaced by a Provost, who will consolidate accountability for the student experience. A key role reporting to the Provost will be the Deputy Vice Chancellor (Education), whose core focus will be on learning and teaching strategy. As a key partner in supporting learning and teaching, the Library will report to the DVC (Education).

Another new key role established in early 2020 is that of Deputy Vice Chancellor (Research), reporting directly to the Vice Chancellor. This appointment's focus is on increasing university-wide research performance and fostering relationships with additional government, industry, and community partners. From the Library's perspective, this has provided an opportunity at a very senior level to advise on the impact on the University of important national initiatives to ensure Australia keeps abreast of global research-focused trends. Additionally, the DVC (Research) and the University Librarian have been using their bi-monthly meetings not only to develop Griffith's responses to these initiatives, as required, but also to identify strategies and resources to maximise the skills and knowledge of library staff to contribute to the University's research agenda. 


\section{Reinventing Library Research Support Services at Griffith University}

Figure 1. Griffith University organisational structure in early 2020. (Source: Griffith University)

\section{GRIFFITH UNIVERSITY ORGANISATIONAL CHART}

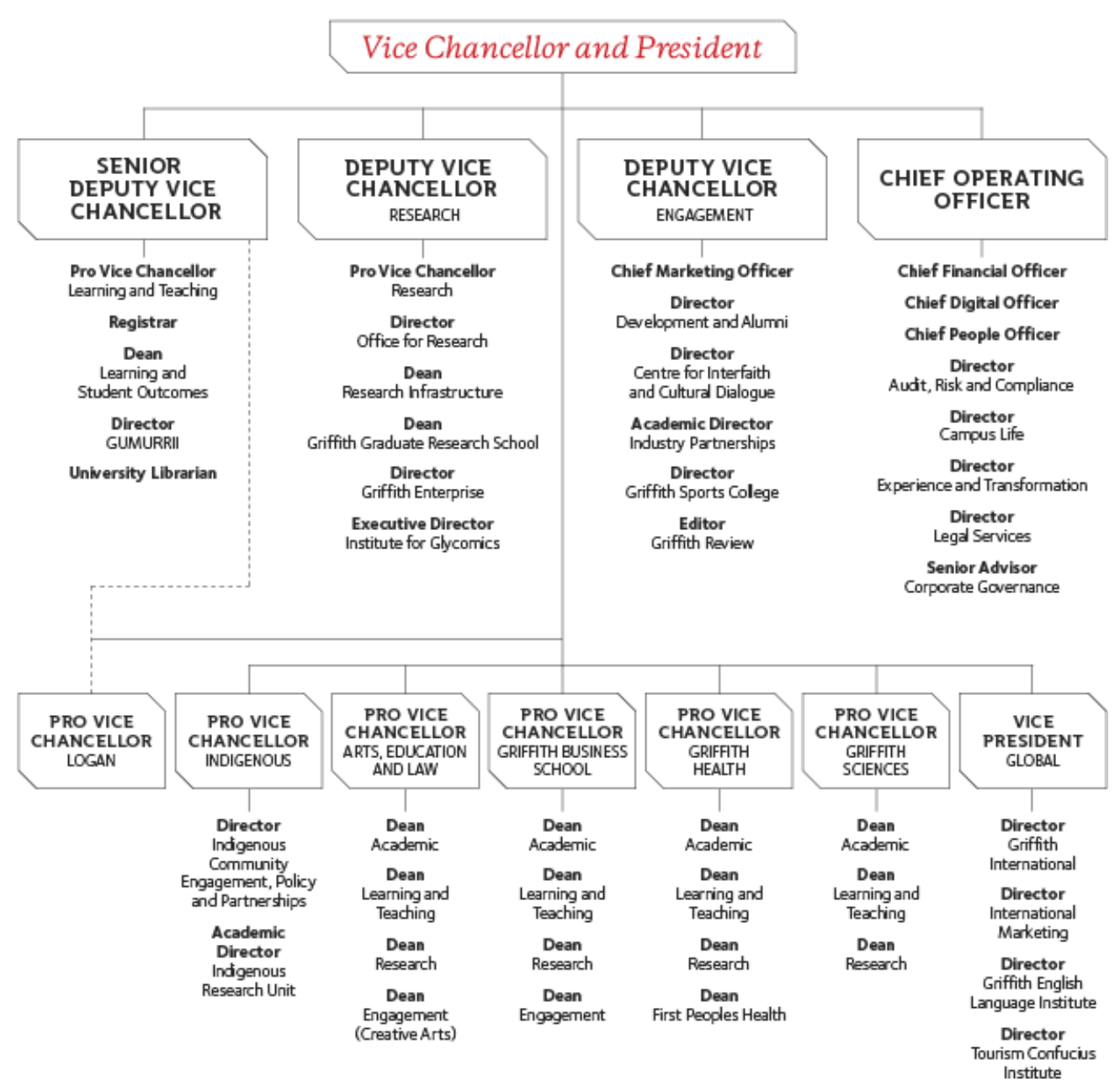

\section{The Library}

From 2012, Griffith University's library services were offered through Information Management (IM) and Library and Learning Services (the Library), two of six Portfolio groups which comprised the then Division of Information Services (INS). In 2017, the Division was disestablished, thereby providing the Library with the opportunity to redefine itself.

A series of subsequent changes have brought all functional units into one portfolio, now known as the Library, which reports to the Senior Deputy Vice Chancellor. In 2018, additional changes established a new service model and staff profile, including a new leadership layer (Figure 2). 
Key drivers were the need to be more responsive to the University's priorities, to facilitate the effective and flexible mobilisation of staff capability, and to facilitate more agile development and delivery of services.

The Library currently provides digital first, contemporary, expert library services to support Griffith University's students, academics and researchers in their learning, teaching and research. The Library delivers high quality, targeted, and robust library management systems, search and discovery tools, and technologies enabling resource discovery, access and use.

Griffith Library encompasses six physical libraries over five campuses and is consistently one of the busiest locations on each of its campuses. The Library also services the University's Digital Campus through a digital first development approach to its services and an e-preferred collection strategy.

Figure 2. Library organisational structure. (Source:Griffith University Library)

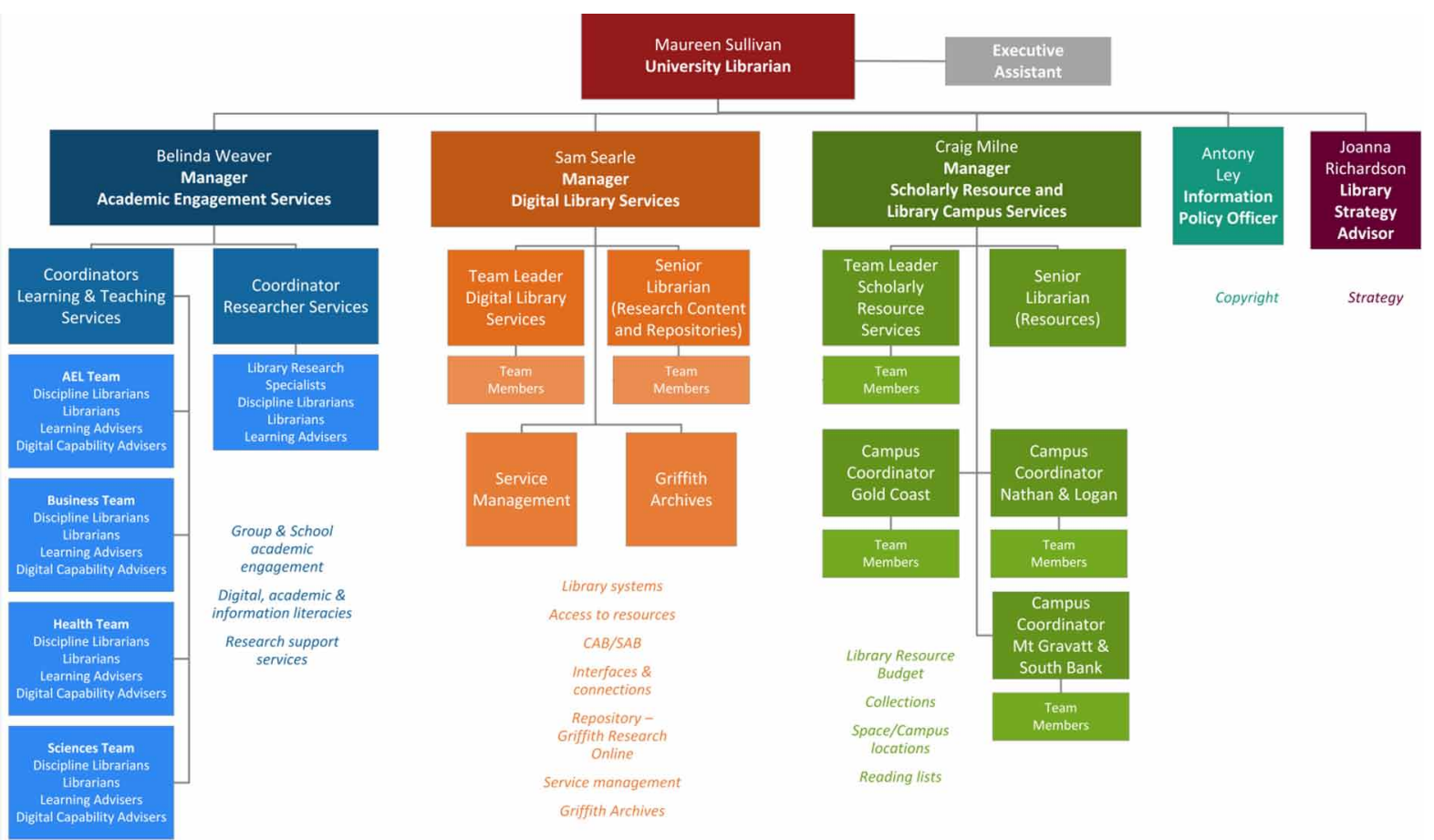

は) Guniffith

As Figure 2 shows, the Library is structured around three key teams:

\section{- $\quad$ Academic Engagement Services}

- Provides generic and discipline-specific information and academic skill development expertise to support learning and teaching and research services.

\section{- Scholarly Resource and Library Campus Services}


- Ensures digital access to information resources that support outstanding scholarship and research anywhere, anytime, as well as first tier support for The Library products and services and operational management of the six campus libraries.

\section{- Digital Library Services}

- Manages the portfolio of technologies and systems that underpin the Library's services.

The Library also includes the University's Information Policy Officer, the Griffith Archive Officer, a Service Management Officer, and a Library Strategy Adviser. has 119 staff, with a full-time equivalent of 105.742 . Full-time staff make up $64.7 \%$ of the overall profile, with the remaining $35.3 \%$ being parttime. Library Campus Services is the largest service group (41.2\% of all The Library staff), servicing all library locations on each campus, with service offerings in face-to face and digital modes (telephone, chat, email, and webform channels). Academic Engagement Services makes up 31.1\% of The Library staffing, as they undertake digital and face-to-face, specialised advice and consulting services for students, academics and researchers.

The Library has benefited from the long history of the design and delivery of integrated divisional (INS) services to a dispersed multi-campus/multi-disciplinary community. For the Library, this established a broad focus on, and understanding of, issues beyond traditional library boundaries. As a result, at the heart of 'how we do things' is a commitment to end-to-end service delivery enacted through data-driven decisions, collaboration based on respect for all expertise and contributions, and an understanding of the porous boundaries both between internal Library work teams and Library delivery partners. This is increasingly regarded by Library business partners as a value-add.

\section{RESEARCH SUPPORT SERVICES IN GRIFFITH UNIVERSITY}

Griffith University supports researchers through a range of different units and sections. The key units are:

- Office for Research - delivers professional research support services with functions spanning grants, development, ethics and integrity, policy, performance and reporting

- Griffith Graduate Research School - administers Higher Degree by Research (HDR) programs, manages placements and internships, and oversees the comprehensive and broad-based Researcher Education and Development (RED) training program, in which the Library collaborates

- Griffith Enterprise - the University's dedicated unit for business and government engagements, innovations and new ventures, which connects research experts to public needs to find solutions for society

- $\quad$ eResearch Services - provides specialist IT support for researchers across all Griffith schools and research centres

- The Library - delivers a broad range of research support services and training to both researchers and HDR students.

\section{Challenges}

Historically, Griffith University Library had established a record within the University of offering a range of research support services for such topics as bibliographic impact, information literacy, and research 
discovery. However, in recent years, it had become readily apparent that if the Library was to continue to contribute to the University's research agenda, then it needed to reconceptualise its service offerings to address modern, data-driven research challenges.

Given the number of Griffith University units with roles in research support, there is inevitably some confusion in researchers' minds as to where to turn for advice, especially regarding issues such as data management, which can span a number of units, or identifying different units' responsibilities in supporting and training HDR students. As stated above, Library staff now need to support the increasing numbers of researchers for whom there is no established tool for the kind of research they want to do. As increasing numbers of staff and HDR students undertake data-intensive research, the importance of appropriate skills, support and training becomes more pressing.

Another emerging challenge is the creation of Griffith 'Beacon' projects, which are large, interdisciplinary projects designed to address some of humanity's grand challenges, such as the health effects of climate change. Traditionally, these projects would have been solely run by schools and research centres, but their size and complexity has fostered a more collaborative approach in which eResearch Services and Library staff can play a key role.

Reliable data on the Library's effectiveness has been scattered. Feedback on individual workshops indicates they have been favourably received by students and staff alike, and a steadily increasing uptick in consultations and workshop requests demonstrates the considerable need for Library support. However, the lack of a centralised data dashboard has hampered the Library's ability to tell this story.

In the sections which follow, the authors have outlined the approach which Griffith University Library is adopting to address the fundamental question raised by this monograph: How does a university library ensure that its research support services contribute to the parent organisation's strategic research goals? Some of the key characteristics covered include

- $\quad$ Library research support staffing profile, including roles

- $\quad$ Target users, including researcher profiles

- Service reorientation plan

- Service catalogue

- Collaboration with other University research support units

The reorganisation is still being bedded down, and it is not yet possible to measure how effective the changes have been in enhancing research outcomes. However, the development of standardised metrics and measurements forms part of the changes being implemented, so that it should be possible in the future to provide evidence of the success of the Library's service changes.

\section{Library Research Support}

The researcher support services offered by the Library are managed by Academic Engagement Services (AES), a team of forty-two staff, not all of whom work full time (the full time equivalent (FTE) is 38.38). AES is divided into two teams, which work across five physical campuses and the Digital Campus. Researchers are also supported by Library Technology Service (LTS), which manages the Griffith Research Online (GRO) repository, in which researchers can deposit openly available research outputs, and by a full time Information Policy Officer, who advises and runs training on copyright and intellectual property. 
Reinventing Library Research Support Services at Griffith University

The focus of Learning and Teaching, the larger of the two AES teams, is to support undergraduate and postgraduate coursework students, manage course resources, provide academic skills, digital and information literacy training via face to face workshops and through bespoke online content, and run consultations with students.

Researcher Services is a smaller team, currently eleven people, including the team coordinator. Staff within the team have different roles, all of which complement each other. The focus of the Researcher Services team is to support academic staff in their research role, as well as HDR students enrolled in either Masters by Research or PhD programs.

The two teams are not silos. They collaborate closely across the continuum of teaching and research support needs and provide strong backing for students moving from undergraduate to postgraduate study.

The Academic Engagement Services (AES) structure was established in 2018, with the aim of creating a more responsive and agile team to foster academic engagement across both teaching and learning and researcher support (Figure 3).

Figure 3. AES structure in 2020. (Source:Griffith University Library)

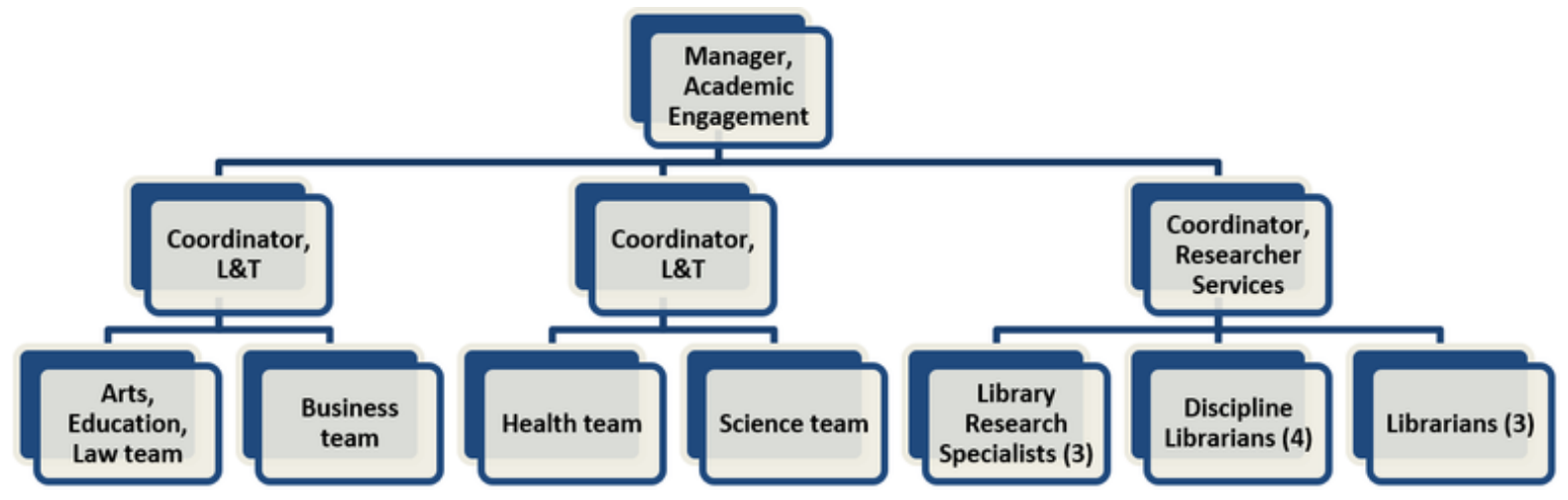

The incoming Manager, Academic Engagement, who began work in November 2018, had previously worked as a community lead for The Carpentries (2020), a global non-profit organisation that teaches foundational computational skills to researchers. Before that, she was a Team Leader for the Queensland Cyber Infrastructure Foundation, a joint operator of the Queensland section of the Australian research cloud with the Research Computing Centre at The University of Queensland. The experience gained in both positions identified a growing need for researchers to develop a range of skills to enable them to work computationally and collaboratively with data. As data volumes have continued to grow in scale and complexity, this need has become more acute, especially since researchers need to comply with increasingly stringent data management and research reproducibility requirements from journal publishers and research funding bodies (Australian Research Council, National Health and Medical Research Council, \& Universities Australia, 2019).

This need provided the impetus to develop and deliver research support of a different kind from that previously offered to researchers by staff in university libraries. While such libraries have traditionally supported scholarly research, and have constantly adapted their services over the years as more and more scholarly practice has moved into the digital space, the paradigm shift to data-driven research meant 
a more radical change was needed if Griffith Library was to stay relevant and provide services of real value to the University and its researchers.

As more and more research becomes data-based and data-driven, and as researchers access and use online resources such as journals in a self-service manner, the need for traditional library support or service mediation has shifted. It is obvious that the information for which researchers seek library assistance is far less in journal, conference, or patent databases - the services that librarians formerly helped them navigate - but rather in data they already have, or are about to create or acquire from a vast range of sources, such as sensors, instruments, telescopes, drones, cameras, acoustic listening devices, imaging technologies, and so on. What researchers now need is advice and skills training on how to work productively and efficiently with that data - how to manage, describe, store, combine, standardise, clean, visualise, analyse, and share it.

Given the Library's changing role in assisting researchers with resource discovery, and the everincreasing existential threats to library jobs from increased automation, it was timely to pivot and use the skills and attributes of librarians to develop new, more relevant services that answered researchers' pressing concerns around working with data, and also contributed to the University's research mission and its strong interdisciplinary focus. The new focus on enabling data-driven research was developed in tandem with updates and extensions of the existing services around researcher profiling and impact and data management.

\section{Increasing Complexity}

While researcher support staff at Griffith have traditionally advised researchers about data management issues such as IP, licensing, the appropriate number of backup copies of data and so on, the kinds of enquiries now being fielded by the team are increasing in complexity.

For example, a Researcher Services staffer recently consulted with a researcher about a three-year funded project examining the health effects of large-scale events within a population. Data for the analysis was being acquired from a number of external sources, such as the Australian Bureau of Meteorology, a range of hospitals and health departments, and state emergency services. Some of the incoming health data was identifiable, and thus highly sensitive. The consultation was wide-ranging, covering issues such as the 'Five Safes' (Desai, Ritchie, \& Welpton, 2016) protocol for managing sensitive data, the optimal data storage for this kind of data, and how to request that storage, estimating the size of the data, issues of access control, file naming and project organisation, tools for working with the data at the different stages from acquisition through to analysis and visualisation, and methods for combining and standardising data sourced from disparate datasets. Issues around the need for staff upskilling were also canvassed. The consultation required good technical knowledge as well as strong communication and problem-solving skills.

Controlling exactly who has access to what project data is another issue on which the Library is increasingly being asked for advice as projects span institutions and countries. Advice has been developed on optimal ways of structuring project data so that permissions and data restrictions can be more easily managed across large research teams.

Protocols are another area in which Griffith's research support is evolving. Where researchers outsource work to external providers for services such as genome sequencing or interview transcription, a clear need has emerged for protocols that protect the data from loss, disclosure or damage as materials are transferred back and forth between the external provider and the research team. Security protocols 
are also needed as staff move in and out of projects or leave the University for other jobs. Researcher services staff are helping researchers develop instruments for research teams, such as data compliance checklists, data induction checklists and workflows for incoming members, and data exit plans for departing staff or graduate students to ensure that no data is accidentally removed.

\section{Reorienting Services}

Traditionally, Griffith University Library staff had offered advice, support and services regarding data management, scholarly publishing, open access, and bibliometrics. They also provided advice and training to HDR students. Services were provided face-to-face and virtually by individual consultations or by bespoke training workshops tailored to students' needs. Web-based support materials, including video content, provided 24/7 support on a range of topics. However, a 2019 review of the Library indicated that Library services, though highly valued, were not well-understood by Library clients. This was a key driver for developing a service catalogue that could be a key explainer of what we do.

Because institutions have been slow to recognise the challenges presented by the data-driven nature of research, this provided an opportunity for Library staff to step in to provide advice, skills training, and support throughout the entirety of the research cycle, from data creation and acquisition to data management, publication and sharing, and its eventual curation and archiving. The Library had seized a similar opportunity when earlier assuming responsibility for data management advice and support, and when helping researchers comply with the data management and research reproducibility requirements set by journal publishers and research funding bodies.

By responding to the increasing complexities of research needs, and recognising a gap in formal training and support, Griffith Library not only developed a plan to reorient library services to support data-intensive research, but also accepted the need for library staff to build new capacity and capability in these emerging areas.

The aim of the service reorientation was to build on existing services, while also developing new services, such as data clean-up and data storytelling, to support the new data-driven research methods in which researchers increasingly work. Establishing the Library as a vital partner in research projects and demonstrating the Library's value within that space was a principal driver for change. Leveraging the interdisciplinary skill set of Researcher Services staff was a key way to demonstrate our value and usefulness to researchers.

\section{Reorientation Plan}

Before new services could be developed and delivered, agreement first had to be reached with staff on what these new services would be, who would deliver them, what deficits in staff skills, knowledge and materials might need to be addressed before services could be developed and launched, and a strategy mapped out on how best to demonstrate and communicate the eventual changes to stakeholders.

The service reorientation plan had the following components:

- Define the services to be offered (a mixture of newly developed and well-established services)

- Clarify roles and responsibilities within the Researcher Services team

- Identify knowledge and skills gaps

- $\quad$ Build a knowledge base 
- Upskill and train staff

- Create service support materials and training

- Deliver the service

- Communicate the changes to stakeholders

To ensure services were well-targeted, consultations were held with a range of research staff, research students, and staff such as HDR convenors about their needs, as well as with staff from other units who support researchers and offer research training at Griffith University.

Within the team, it was important to ensure that Researcher Services staff had the requisite skills and the knowledge to be able to create, deliver and support new services. Also important was ensuring that staff had sufficient confidence to take on new or unfamiliar areas of work. While the idea of developing new services was not unwelcome to staff, one immediate issue that had to be addressed was gaps in knowledge. Another was the need to address the 'impostor syndrome' some staff were experiencing at the idea of presenting themselves as 'experts' in areas where their knowledge was either quite shallow or, in some cases, non-existent. For example, some staff were unfamiliar with the terminology needed to adequately discuss and support data-driven research. Technical skills had to be updated, for example, around data clean up and weighing up the suitability of different kinds of cloud-based data storage for different research scenarios, and with new data handling protocols such as Five Safes (Desai, Ritchie, \& Welpton, 2016), which provided a framework for all researchers working with potentially sensitive data.

Internally, a number of staff sessions were run to define and refine service offerings, to clarify staff roles and responsibilities, and to set expectations. Upskilling sessions around data wrangling and effective and inclusive teaching practices were also delivered. A comprehensive, collaborative knowledge base was created to equip staff with the information required to support the mixture of new and evolving services. A new service catalogue was drafted, which explains what each new or existing service is, who can access it, and how, and other relevant detail. The service catalogue is structured around key areas - data management; scholarly publishing and research impact; and open scholarship and data wrangling. Data wrangling was a new area, and the support for this service needed to be built completely from scratch. We also offer largely HDR-student-targeted services, such as working with literature and developing skills in academic writing.

\section{Knowledge Base}

Knowledge gaps were centred around research-related topics, as well as disciplinary differences and their variable impacts on research support. The Discipline Librarians generally had deeper knowledge about the discipline areas they traditionally supported than did other staff, but if Researcher Services staff across the board were to support interdisciplinary research, knowledge gaps of all kinds had to be minimised as far as possible. To address these gaps, the creation of a Knowledge Base was undertaken, with two types of document being created:

- Documents addressing a specific topic of relevance to emerging services, for example, APIs, issues around options for data storage, cybersecurity and data encryption, algorithms, web scraping

- Documents describing discipline-specific research environments, for example, data storage challenges within a discipline, research impact points of difference within a discipline. 


\section{Reinventing Library Research Support Services at Griffith University}

There were approximately fifty initial topics needing to be created in the Knowledge Base. This has now grown to around sixty and will continue to grow.

Collaboratively created documents in the Knowledge Base captured the existing knowledge about each of the designated topics from within the team, and identified where information was lacking or where deeper or more current information needed to be sourced. The iterative nature of these documents' creation meant that formerly siloed knowledge could be pooled and shared. Documents had multiple purposes: (i) to provide the team with a comprehensive and authoritative look-up service on a topic when asked by researchers for advice; (ii) to provide the basis for the new web-based, Tier 0 support that still needed to be developed as part of the service revamp; and (iii) to encourage sharing of knowledge and a more collaborative and coordinated approach across the team.

A standard format for both types of knowledge base documents has been implemented (Tables 1 and 2).

Table 1. Topical template (Source:Griffith University Library)

\begin{tabular}{|l|l|}
\hline \multicolumn{2}{|c|}{ Body of Knowledge Template } \\
\hline Definition & A brief summary of the topic, usually one to two sentences \\
\hline Uses & $\begin{array}{l}\text { How the topic is relevant and where it fits into a research support } \\
\text { scenario }\end{array}$ \\
\hline Examples of specific discipline methods and issues & Useful analogies for discussions with researchers \\
\hline $\begin{array}{l}\text { Organisations active in creating, collecting, analysing or } \\
\text { lobbying for [this Knowledge Base topic] }\end{array}$ & Key organisations to watch for developments in the field \\
\hline Web sites for further information & \\
\hline Tools & Relevant tools, e.g., for data visualisation, data clean up \\
\hline Griffith University stakeholders & If relevant \\
\hline Research evidence that [this Knowledge Base topic] matters & Current academic journal articles and papers relating to the topic \\
\hline Designated person responsible for maintenance & Staff name \\
\hline Backup person for maintenance & Staff name \\
\hline Tags & Categories to enable cross-Knowledge Base searching \\
\hline Date created \& author & Date and staff name \\
\hline Date updated & \\
\hline Next review date & \\
\hline
\end{tabular}

In addition to creating the topical Knowledge Base, Researcher Services staff also sought to map the different research environments in which HDR students and researchers operate. This was to help new and developing researchers gain a broad sense of the discipline in which they would be researching, identify the key research methods and tools, learn about the key sources of research data used in their discipline, and so on.

For each discipline supported at Griffith University, Researcher Services staff sought to map them broadly, according to six key sections:

- $\quad$ Research tools, such as

- Databases relevant to the research 
Reinventing Library Research Support Services at Griffith University

Table 2. Discipline-specific research environment template (Source:Griffith University Library)

\begin{tabular}{|l|l|}
\hline \multicolumn{2}{|c|}{ Discipline-Specific Research Environment Template } \\
\hline What the discipline encompasses & Brief summary \\
\hline Data sources in the discipline & $\begin{array}{l}\text { Databases, data repositories, government, NGO, institutional and } \\
\text { industry sources }\end{array}$ \\
\hline Common analytical tools & Relevant tools, e.g., for data visualisation, data clean up \\
\hline Support available & \\
\hline Training available & \\
\hline Research methods most common within the discipline & e.g., grounded theory, prototyping, species distribution modelling \\
\hline Research scenarios & Recent real world examples \\
\hline Relevant scholarly articles & Current academic journal articles and papers \\
\hline Griffith University institutes or centres & If relevant \\
\hline $\begin{array}{l}\text { Designated person responsible for maintenance of [this } \\
\text { Knowledge Base] }\end{array}$ & \\
\hline Backup person for maintenance of this Knowledge Base & \\
\hline Tags & Categories to enable cross-Body-of-Knowledge searching \\
\hline Date created \& author & Date and staff name \\
\hline Date updated & \\
\hline Next review date & \\
\hline
\end{tabular}

- Computer programs, including writing and spreadsheeting tools

- Analytical tools, such as R

- Referencing tools for managing bibliographies

- Relevant data sources, such as

- Surveys and interviews

- Texts/corpora

- Video/audio

- Organisations, such as NGOs, governments, industry bodies

- Libraries, museums and archives

- $\quad$ Research methods relevant to the research discipline, e.g., discourse analysis, prototyping

- Scenarios to assist researchers in developing appropriate research questions within a discipline, including sizing and scoping of projects

- Training available, both internal and external

- Support services, both internal and external.

This mapping has proved helpful to librarians who increasingly need to support interdisciplinary research. The discipline-specific mapping documents (Table 2) have helped people unfamiliar with a discipline get up to speed quite quickly on the major landmarks within it, and have also been useful in assisting with new staff induction. They have also served to democratise information across the team all staff, including those in the Learning and Teaching team within AES, have access to the same data. Mapped environments discourage knowledge 'hoarding' by team members. 
Reinventing Library Research Support Services at Griffith University

Sharing this kind of data also makes it easier for people to switch roles, or to deputise for others, both of which are useful for multi-skilling and career development.

The collaborative nature of the development of the documents means that information has been captured from a range of different people's experiences, and is all the richer for it. Where information was seen to be missing, and where it needed to be sourced from elsewhere, the central capture of the information has made that deficit visible to all, and therefore identifiable as work still needing to be completed.

While all the topical and disciplinary documents have been created as standalone documents, housed centrally within a Microsoft Teams file structure, a project is underway to convert the data contained within them into a structured format so that the material can be housed on SharePoint and become searchable through document metadata. The categorisation of items by multiple tags is designed to link relevant information together for retrieval purposes.

\section{Staffing and Roles}

Researcher Services' key stakeholders at Griffith University include Academic Groups, research institutes and centres, and HDR candidates. Griffith is currently divided into four key academic groups:

- $\quad$ Arts, Education and Law (AEL)

- Business

- Health

- Science

Advice and services are tailored to the needs of these four Academic Groups and to the many research centres and institutes linked with those Groups at the University. All librarian roles within Researcher Services support Digital Science's Symplectic Elements (housing research publications) and Discovery (the researcher profile service locally badged as Griffith Experts) services, and all topical advice is informed by disciplinary differences and knowledge.

The four Discipline Librarians based in the Researcher Services team have each been assigned primary responsibility for a specific academic group so that communication and outreach are consistent and well-managed. They work closely with their Discipline Librarian counterparts within the Learning and Teaching team, whose four teams are based around the same academic groups. This ensures more consistent service right across the board. The Researcher Services Discipline Librarians lead the outreach and communication work with the academic groups, and play a key role in supporting and upskilling HDR students and supporting researchers.

The librarians within the team focus on service delivery, managing and triaging requests submitted through the online enquiry system, running consultations, teaching workshops, and providing support for Griffith's Symplectic Elements and Discovery services. They support the work of the Discipline Librarians and the Library Research Specialists as required and play a key role in onward referral across a range of topics such as researcher profiles, research metrics, and data handling issues.

The three Library Research Specialists (LRSs) have distinct areas of operation, with one focusing on developing expertise in data management, another on scholarly publishing and research metrics, and the third working in the emerging support area of data wrangling and open scholarship. These unique roles were established to support the reorientation of the service focus and are required to develop the deep 
knowledge required to stay on top of changing needs and emerging trends in their areas of specialisation (see Table 3).

Table 3. Library research specialist roles (Source:Griffith University Library)

\begin{tabular}{|l|l|l|}
\hline \multicolumn{1}{|c|}{ Data Management } & Data Wrangling and Open Scholarship & \multicolumn{1}{c|}{$\begin{array}{c}\text { Scholarly Publishing and Research } \\
\text { Metrics }\end{array}$} \\
\hline $\begin{array}{l}\text { The LRS for data management has been } \\
\text { at the forefront of developing the various } \\
\text { data compliance and data exit instruments } \\
\text { and checklists requested by research teams, } \\
\text { creating advice about the management } \\
\text { and storage of all kinds of data, and what } \\
\text { adherence to the Five Safes framework for } \\
\text { sensitive data would entail, and building } \\
\text { expertise in the REDCap software used for } \\
\text { acquiring and managing clinical trials data. }\end{array}$ & $\begin{array}{l}\text { The LRS for data wrangling has developed } \\
\text { and delivered new workshops on fixing } \\
\text { messy, missing and inconsistent data and } \\
\text { on acquiring and merging data from a range } \\
\text { of publicly available sources. An existing } \\
\text { data storytelling workshop now has an extra } \\
\text { focus on freely available tools to visualise } \\
\text { data. This role is also developing advocacy } \\
\text { and training materials and practical advice } \\
\text { around open scholarship. }\end{array}$ & $\begin{array}{l}\text { The LRS for the scholarly publishing and } \\
\text { research metrics specialisation delivers and } \\
\text { supports traditional services and advice } \\
\text { in this area and also focuses on helping } \\
\text { create and disseminate stories of the } \\
\text { beneficial societal impacts Griffith research } \\
\text { has. This impact may take the form of } \\
\text { new policies or protocols, legislative } \\
\text { changes, improvements in health and the } \\
\text { environment and other useful outcomes. }\end{array}$ \\
\hline
\end{tabular}

The success of this approach, i.e. of 'specialist' leads coupled with professionally engaged and upskilled library staff providing in-demand services, can be seen in the growing inclusion and integration of what would once have been seen as 'library-only' training into university-wide offerings, and ever-increasing cooperation and collaboration between the Library and other units at Griffith who all support research and researchers in different ways.

The Library Research Specialist roles are relatively new, and thus are still evolving. Given the Discipline Librarians' focus on building up knowledge and experience within their subject areas, the Library Research Specialist roles were created to provide leadership in the topical, more future-facing aspects of researcher support, such as evolving funder and journal policies on data management and reproducible research, the growing use of computational methods in research, the need for data-driven research support, and so on.

The aim was to build a warp/weft support structure to ensure that all services are well-grounded and fit for purpose.

- The Warp: Discipline Librarians, supported by librarians in the team, provide the disciplinary expertise to ensure all advice encompasses disciplinary differences around research impact, data management, data wrangling, and open scholarship. This advice is based on collaboratively developed, discipline-specific backgrounding documentation.

- The Weft: Library Research Specialists provide the topical knowledge to ensure all advice is indepth and fit for purpose. This advice is based on collaboratively developed bodies of knowledge about a whole range of topics, issues and research-related challenges.

Services are built around three main outreach channels - web-based information (self-help information resources, which need to be constantly updated), training workshops, and advice and support, usually managed through a consultation which may be conducted face-to-face, online, or by phone. Information used in consultations is in many cases drawn from, and is certainly informed by, the evolving Researcher Services Knowledge Base. To request support, researchers, including students, generally use an enquiry 
Reinventing Library Research Support Services at Griffith University

management system, with options tailored for each client group. Queries are routed to the appropriate team by question category, that is, queries about academic writing might be routed to a learning adviser, while questions about researcher profiles go to the librarian queue, and a question about data licensing would be sent to the library research specialist queue. The system allows the query to be routed to different service units outside of AES, or to different queues within Researcher Services. Services are tiered, running numerically from 0 (self-help) to 3 (specialised level) as indicated in Table 4.

Table 4. Service tiers and their meaning (Source:Griffith University Library)

\begin{tabular}{|l|l|l|}
\hline \multicolumn{1}{|c|}{ Level } & \multicolumn{1}{|c|}{ Description } & \multicolumn{1}{c|}{ Support } \\
\hline Tier 0 & $\begin{array}{l}\text { Self-help and user-retrieved } \\
\text { information }\end{array}$ & $\begin{array}{l}\text { Users retrieve information and use resources in a self-service manner. } \\
\text { Outstanding needs and enquiries not satisfied by this material can be escalated by means } \\
\text { of an enquiry-logging system. }\end{array}$ \\
\hline Tier 1 & $\begin{array}{l}\text { Help for known needs and } \\
\text { guided introduction to Tier 0 } \\
\text { support }\end{array}$ & $\begin{array}{l}\text { Staff with introductory knowledge support initial enquiries and } \\
\text { escalate more complex issues to a higher tier. }\end{array}$ \\
\hline Tier 2 & $\begin{array}{l}\text { Targeted support and technical } \\
\text { advice }\end{array}$ & Experienced and knowledgeable staff assess issues and identify solutions. \\
\hline Tier 3 & $\begin{array}{l}\text { Expert or highly specialised } \\
\text { support }\end{array}$ & Highest level of response. \\
\hline
\end{tabular}

Underpinning the tiered structure are our key service principles, which include a user-centred focus in the design and delivery of services, and the need for all services to be connected, integrated, and personalised, as well as fit for purpose.

\section{Service Catalogue}

Services are offered through a combination of online and face-to-face delivery. As a multi-campus university, Griffith is well set up to deliver services remotely, whether through web-based resources, training workshops, or via online meetings or consultations. However, staff at the different campuses also regularly meet in person with students or staff who need support. Currently, most training is delivered in person at least at the two largest campuses, Nathan and Gold Coast, and some training is delivered at all five.

Researcher Services are described in a service catalogue. We are currently promoting six, with two more to be included once the appropriate web support materials for them have been finalised.

The initial six services are:

\section{- Working with data}

- This new, broader service updates and extends the existing support which was largely based around data management. It now offers support across the entirety of the research data lifecycle, from the creation, acquisition and storage of data through to publication and archiving, providing clarity about licensing, data sharing and reuse, and other data-related issues. This service incorporates the data wrangling and data clean-up training the team developed during 2019. It also includes data storytelling and tools for visualisation. Staff are being trained in how to conduct a much wider-ranging data interview than before - one that goes beyond 
issues around storage, back-up options and re-use to further probe desired data use workflows, the optimal co-location of data and tools, methods for remote collaboration over data, especially sensitive data, so as to help researchers tailor a solution that meets their unique needs. Plans are being developed to make the newly created data wrangling lesson materials openly available to other libraries, most likely through a GitHub repository.

- $\quad$ Researcher metrics

- This provides advice and support for a range of research metrics services, such as Clarivate Analytics' tool InCites, and also covers the use of altmetrics and social media for research promotion.

- $\quad$ Researcher profiles

- This provides advice and support for the Griffith Experts profiling service (based on Symplectic's Discovery tool) and for other services such as ORCiD and Google Scholar. Staff are being trained in how researchers can maximise their profile's visibility and share profile data across services such as ORCiD.

\section{- Scholarly publishing}

- This provides advice and support on where to publish, the pros and cons of open access publishing, and how to avoid publishing scams and identify predatory publishers. As it covers issues such as bibliometrics and altmetrics, there is some overlap with the Researcher metrics service.

\section{- Open scholarship}

- This provides advice and support on how and why to work 'in the open'. It includes advice and support on how to make publications and data 'FAIR', i.e. Findable, Accessible, Interoperable, and Reusable (Wilkinson et al., 2016).

\section{- Working with literature}

- This provides advice and support on finding and managing resources for literature reviews. Advice on techniques for faster reading and processing of published research is also provided. This service is largely designed for, but is not restricted to, HDR students. Workshops for this service are taught by a combination of Researcher Services librarians and Learning Advisers from the Teaching and Learning team who, in most cases, are qualified teachers. Staff also provide advice through individual consultations.

The seventh service in development, Academic Writing, will help HDR students master the skills required to construct strong academic arguments and adequately structure their writing to suit different genres. Workshops and advice for this service are provided by Learning Advisers from the Teaching and Learning team. They also provide advice specifically targeted for the needs of HDR students through individual consultations. Staff are already performing this work - all that is lacking is the Tier 0 material for the service catalogue.

The eighth service is a guide to the research ecosystem, that is, information about the policies, organisations, facilities, support services, and training that underpin research, as this is often an area in which both HDR students and researchers alike lack up-to-date knowledge. Work is ongoing to map this.

AES staff have now presented their service catalogue via the researcher support section of Griffith Library's website. The plan is to gradually add more materials to the initial pages, including online tutorials and self-help guides, in a constantly iterative improvement process. 
Reinventing Library Research Support Services at Griffith University

The audience for Researcher Services includes all research-active academic staff and HDR students. Some of the services, such as Working with literature, and the forthcoming Academic Writing service, are geared more toward HDR students than academic staff.

The implementation in late 2019 of more rigorous enquiry management reporting and categorization should provide new evidence of the uptake of the different services.

\section{Supporting Researchers on Different Paths}

Researcher Services staff will increasingly need to support researchers developing bespoke tools to answer their research questions. The issue here is the lack of available training (except for disciplines such as computer science) to develop computational thinking as a key research literacy.

Margulieux (2017) describes computational thinking (CT) as "a set of skills related to computing but useful beyond computing. This conception originated from Wing's (2006) paper that argued CT should be as fundamental to education as reading, writing, and arithmetic". In layman's terms, computational thinking encompasses the steps required to formulate a problem and find a method to solve it, either by a person or by a computer. Because it involves discrete steps, computational thinking is sometimes referred to as algorithmic thinking.

Given the key role computational thinking plays in problem solving, it is already showing up in workforce planning as one of the most sought-after graduate attributes (Hershkovitz, Sitman, R., Israel-Fishelson, Eguíluz, Garaizar, \& Guenaga et al., 2019). Researcher Services are investigating the development of an introduction to computational thinking to assist researchers starting down this path.

Researchers at Griffith University who want to master foundational computational skills can attend Software Carpentry workshops which are offered throughout the year. These locally run, volunteer-led workshops, while not explicitly teaching computational thinking, do introduce researchers to basic skills such as task automation, version control, and the rudiments of programming in R or Python. Griffith Library staff refer researchers to these workshops and also volunteer as helpers at some of the workshops. There are four certified Software Carpentry instructors within AES, two of whom are also Software Carpentry instructor trainers.

The majority of AES staff, i.e. not just those in Researcher Services, have now attended an internally run, two-day workshop to learn and practise the methods that have made Software Carpentry workshops so successful. These include collaborative learning using 'code-along' methods, the use of continuous feedback, working at the learners' pace, the use of challenges to test understanding, and many more, with the key ingredient being the creation of an inclusive and welcoming learning environment. The internal workshop was based on the materials shared in The Carpentries' Instructor Training website (The Carpentries, 2019). Staff have been encouraged to adopt these practices to make all AES workshops more interactive, inclusive, welcoming and engaging.

\section{Building Cross-Unit Cooperation}

The Researcher Services team have strong relationships with other units who support research and researchers within the University. All AES-initiated workshops designed for researchers are offered through the Researcher Education and Development program, which is coordinated by the Griffith Graduate Research School (GGRS). GGRS also created a Research Support Community of Practice (CoP) in 2019. This group meets regularly and is open to anyone whose role involves research support. This has proved 
to be an important knowledge exchange mechanism, and has created greater understanding about who does what, and how services and support across Griffith join up. Researcher Services staff are active in the CoP. The team also has strong relationships with staff in the Office for Research, which manages research grants and research development. Grants recipients are now referred to the Library for support around data management planning, and the Office refers staff to library-created guidelines on this topic. Library staff are also front-line responders to Office for Research-owned services, such as Symplectic Elements (research publications) and Discovery (researcher profiles). The Library's relationship with eResearch Services is also strong. Some material is co-taught, including Software Carpentry workshops; staff co-operate on providing support and advice at weekly drop-in sessions called Hacky Hours; both units collaboratively organise and help deliver the annual Research Bazaar three-day skill and community building events for early career researchers; and staff have regular contact and conversations regarding services, tools, plans and projects.

Within the Library, AES staff cooperate with their colleagues in the Library Technology Service (LTS), who manage the Griffith Research Online repository (GRO), which makes available open access versions of published works. In 2020, staff in LTS and AES plan to collaborate more closely to raise the profile of existing deposited works and to advocate for and provide resources to support researchers interested in open scholarship and data curation.

\section{FUTURE RESEARCH DIRECTIONS}

In 2020, Researcher Services will partner with a range of schools to deliver introductory research training to incoming HDR students, so that they can be highly productive researchers from the start. Training will cover a broad range of skills and tools. This will be a rolling pilot program that will be delivered in stages and continuously evaluated as the cohort moves through their HDR candidatures. The aim is to assess whether targeted training at point of need adds value to the HDR process.

During this year, staff in Researcher Services will also support researchers working on 'Beacon' projects - these are flagship projects that seek to address very large interdisciplinary research challenges in a coordinated way. Library input will be documented and assessed to extract learnings from these projects that can feed into upskilling and service improvement.

Greater emphasis is also being put on outreach to new grant awardees so that good research and data management practices can be implemented from the outset and skill gaps in the research team identified early, and to ensure that suitable arrangements are made before work commences to ensure the long-term sustainability and potential operationalisation of project data, so that projects do not become 'orphaned' when funding runs out.

Additionally, a data working group has been established within AES to centralise and analyse disparate data, such as workshop requests, training feedback, research support-related data from the Library's enquiry management system, and data from library drop-in sessions and attendance at Hacky Hours. The aim is to ensure that all services are aligned to need and are evidence-based. The group is also developing a data handling protocol, which can be repurposed as a customisable instrument for dissemination to researchers. 
Reinventing Library Research Support Services at Griffith University

\section{CONCLUSION}

A university's aspirations to increase both its research activity and impact rely not only on the outputs of its researchers but also on the quality of the research support provided by a range of key service elements within the organisation. It is here that the library can make a valuable contribution. In recognising this challenge, Griffith University Library has embarked on a major reconceptualisation and restructure of its research support services, in alignment with the University's strategic research goals.

The changes to researcher support at the Library are still in the process of being fully implemented, so it is not yet possible to fully gauge the success or otherwise of the changes made, or to evaluate their effect on the University's research performance. Work is still ongoing to equip the team with the skills they need to support data-driven research and meet future needs. The changes to service this year have been implemented to ensure that Griffith University Library has a fit-for-purpose team, which is wellpositioned to partner with researchers in the grand interdisciplinary research challenges they face.

\section{REFERENCES}

Australia. Department of Education and Training. (2019). National collaborative research infrastructure strategy. Canberra: The Department. Retrieved December 18, 2019, from https://www.education.gov. $\mathrm{au} /$ national-collaborative-research-infrastructure-strategy-ncris

Australia. Department of Innovation, Industry, Science and Research, (2010). National collaborative research infrastructure evaluation report. Canberra: The Department. Retrieved January 9, 2020, from https://docs.education.gov.au/ system/files/doc/other/national_collaborative_research_infrastructure_ strategy_evaluation_report_2010.pdf

Australian Research Data Commons. (2019). The Australian eResearch Skilled Workforce Summit. Retrieved December 18, 2019, from https://ardc.edu.au/events/the-australian-eresearch-skilled-workforce-summit/

Boulton, G., Campbell, P., Collins, B., Elias, P., Hall, W., Laurie, G., . . Walport, M. (2012). Science as an open enterprise. London, UK: The Royal Society. Retrieved December 18, 2019, from https:// royalsociety.org/-/media/policy/projects/sape/2012-06-20-saoe.pdf

Desai, T., Ritchie, F., \& Welpton, R. (2016). Five Safes: designing data access for research. Bristol, UK: University of the West of England. Retrieved April 27, 2020 from https://uwe-repository.worktribe. com/preview/914753/1601.pdf

Fernández-Marcial, V., Costa,L., \& González-Solar,L. (2016). Top universities, top libraries: do research services in academic libraries contribute to university output? In Proceedings of the IATUL Conferences:2016. West Lafayette, IN: Purdue University Libraries. Retrieved April 2, 2020, from https://docs. lib.purdue.edu/iatul/2016/spaces/2

Griffith University. (2019). Creating a future for all; Strategic plan 2020-2025. Brisbane, Australia: Griffith University. Retrieved April 27, 2020 from https://www.griffith.edu.au/office-vice-chancellor/ strategic-plan 
Hershkovitz, A., Sitman, R., Israel-Fishelson, R., Eguíluz, A., Garaizar, P., \& Guenaga, M. (2019). Creativity in the acquisition of computational thinking. Interactive Learning Environments, 27(5-6), 628-644. doi:10.1080/10494820.2019.1610451

Hey, T., Tansley, S., \& Tolle, K. (2009). The fourth paradigm: data-intensive scientific discovery. Microsoft Research.

Katz, D. S., Niemeyer, K. E., Gesing, S., Hwang, L., Bangerth, W., Hettrick, S., ... Allen, A. (2017). Report on the Fourth Workshop on Sustainable Software for Science: Practice and Experiences (WSSSPE4). Journal of Open Research Software, 6(1), 1-10. doi:10.5334/jors.184

MacArthur, D. (2009, March 18). Why biology students should learn how to program. Wired. Retrieved April 27,2020 fromhttps://www.wired.com/2009/03/why-biology-students-should-learn-how-to-program/

Margulieux, L. (2017, April 5). Article summary: Tedre \& Denning (2016) The long quest for computational thinking. Retrieved from https://laurenmarg.com/2017/04/05/article-summary-tedre-denning2016-the-long-quest-for-computational-thinking/

O'Brien, L. (2010). Innovation, university research and information infrastructure: making sound investments in information infrastructure. Paper presented at EUNIS International Congress, Warsaw, Poland.

Oakleaf, M. (2010). The value of academic libraries: a comprehensive research review and report. Association of College and Research Libraries.

Quacquarelli Symonds. (2019). QS Top 50 Under 50 2020. Retrieved December 17, 2019, from https:// www.topuniversities.com/university-rankings-articles/top-50-under-50-next-50-under-50/qs-top-50under-50-2020

The Carpentries. (2019). Instructor training. Retrieved April 27, 2020 from https://carpentries.github. io/instructor-training/

Times Higher Education. (2019). Times Higher Education Young University Rankings 2019. Retrieved December 17, 2019, from https://www.timeshighereducation.com/student/best-universities/best-younguniversities-world

Wilkinson, M. D., Dumontier, M., Aalbersberg, I. J., Appleton, G., Axton, M., Baak, A., ... Bouwman, J. (2016). The FAIR guiding principles for scientific data management and stewardship. Scientific Data, 3(1), 160018. doi:10.1038data.2016.18 PMID:26978244

Wolski, M., Richardson, J., \& Rebollo, R. (2011). Shared benefits from exposing research data. Libraries for an Open Environment: Strategies, Technologies, and Partnerships. Proceedings of the32nd IATUL Conferences. Retrieved January 9, 2020, from https://docs.lib.purdue.edu/iatul/2011/papers/5/ 


\section{KEY TERMS AND DEFINITIONS}

Data-Intensive Scientific Model: In this model, data is captured by instruments or generated by simulators, and as the outputs are too large to be processed by humans, they require software tools to make sense of them.

Discipline Librarians: Senior librarians who support and liaise with specific academic disciplinary groups.

Five Safes: A framework that requires data management decisions to be based on appropriate use against five key criteria: projects, people, settings, data, and outputs.

Fourth Paradigm: A theory that data exploration represents a new scientific paradigm, above and beyond the existing scientific models of empiricism, theoretical science, and computational science.

Library Research Specialist: A senior librarian who leads a discrete area of research support (e.g., data management, bibliometrics, and research impact).

Portfolio: An arrangement of services within a specific grouping. 